\title{
LA UNIÓN PATRIÓTICA: MEMORIAS PARA LA PAZ Y LA DEMOCRACIA
}

\author{
The Patriotic Union: Memories for Peace and Democracy
}

\author{
Unión Patriótica: memórias para a paz e a democracia
}

\section{RESUMEN}

En este texto se plantea el surgimiento y el accionar político de la Unión Patriótica, así como el exterminio sistemático a que fueron sometidos sus militantes y simpatizantes en el curso de las décadas de 1980 y 1990. Este exterminio político es visto como producto de la intolerancia política, el cual se llevó a cabo a partir de un conjunto de planes diseñados y ejecutados para establecer estrategias y métodos de eliminación en diversas modalidades. A partir de fuentes secundarias y aportes metodológicos de las ciencias sociales, se trata la importancia de los procesos de reconstrucción de la memoria histórica que han venido adelantando las víctimas del genocidio contra la Unión Patriótica, que, además de dignificarlas, les está permitiendo dar pasos hacia la búsqueda de la verdad, la justicia, la reparación y las garantías de no repetición. Sin embargo, se pone de presente la complejidad de estos procesos de reconstrucción de memoria en Colombia en cuanto se enmarcan en un conflicto armado que todavía no cesa y, por tanto, genera múltiples tensiones y desafíos.

PALABRAS ClAVE: Unión Patriótica, memoria, verdad, justicia, reparación, genocidio.

\section{EVALUADO: 29 DE ENERO DE 2016}

\author{
Yaneth Mora Hernández (Colombia) \\ Instituto Colombiano de Antropología e \\ Historia \\ Máster en Gestión del Patrimonio Cultural \\ yanethmorah@gmail.com
}

\section{en}

\section{ABSTRACT}

This text covers the emergence and political action of the UP as well as the systematic extinction of its members during these decades. This political extinction is the result of the political intolerance carried out through plans executed to establish elimination strategies and methods within different sectors. We used secondary sources and methodological contributions of social sciences to study the importance of the reconstruction processes performed in order to highlight the historical memory the victims of the UP genocide represent. This aims to dignify them and to search for truth, justice, reparation, and a non-repetition guarantee. However, it is important to note the complexity of these reconstruction processes in Colombia due to the endless armed conflict existing, which generates tension and challenges.

KEYWORDS: Patriotic Union, memory, truth, justice, reparation, genocide. por

\section{RESUMO}

Em este texto se aborda o surgimento e acionar político da UP, assim como o extermínio sistemático a que foram sometidos os seus militantes e simpatizantes no curso dos anos 80 e 90 . Este extermínio político é visto como produto da intolerância política, o qual se levou a cabo a partir de um conjunto de planos desenhados e executados para estabelecer estratégias e métodos de eliminação em diversas modalidades. A partir de fontes secundárias e aportes metodológicos das Ciências Sociais aborda-se a importância dos processos de reconstrução da sua memória histórica que têm vindo adiantando as vítimas do genocídio contra a UP, que além do mais de dignificá-las, lhes está permitindo dar passos para a procura da verdade, a justiça, a reparação e as garantias de não repetição. Porém, põe-se de presente a complexidade de estes processos de reconstrução de memória na Colômbia em tanto se enquadram num conflito armado que ainda não cessa $\mathrm{e}$, por tanto, gera múltiplas tensões e desafios.

PalavRas ChaVE: Unión Patriótica, memória, verdade, justiça, reparação, genocídio.

PARA CITAR ESTE ARTÍCULO/TO CITE THIS ARTICLE/PARA CITAR ESTE ARTIGO:

Hernández Mora, Y. (2016), La Unión Patriótica: memorias para la paz y la democracia. Panorama, 10(18) pp. 27-38. 


\section{LA RECONSTRUCCIÓN DE LA MEMORIA HISTÓRICA DE LA UNIÓN PATRIÓTICA}

La Unión Patriótica (UP) es un nombre que implica Yaneth Mora Hernández I diferentes significados: un proyecto político y democrático de convergencia de diferentes sectores, un partido que fue objeto de un genocidio o una apuesta política que buscó cambiar las estructuras antidemocráticas del país. Cada uno de estos significados hace parte de la memoria de las víctimas y los sobrevivientes de este movimiento.

La memoria no es unívoca u homogénea, sino, por el contrario, es múltiple, como lo son las vivencias mismas. Por ello, parece más adecuado hablar de las memorias, en plural, que de una memoria única. Esta multiplicidad de experiencias da lugar a muchos relatos distintos, contradictorios y ambivalentes. Su riqueza reside en permitir que conviva lo contrapuesto para dejar que emerja la complejidad de los fenómenos, pero también para abrir paso a diferentes relatos (Calveiro, 2006).

Los procesos de reconstrucción de memoria histórica en Colombia no dejan de ser complejos, puesto que se enmarcan en un conflicto armado que todavía no cesa y, por tanto, genera múltiples miedos y silencios. No obstante, la importancia de estos procesos es fundamental en cuanto la memoria histórica es un escenario para el diálogo, la negociación y el reconocimiento de las diferencias con miras a un proyecto democrático e incluyente de superación del conflicto armado (Comisión Nacional de Reparación y Reconciliación, Área de Memoria Histórica, 2009). Asimismo, la memoria histórica puede entenderse como un mecanismo de empoderamiento de las víctimas por la búsqueda de la verdad, la justicia, la reparación integral y las garantías de no repetición, como derechos inalienables.

Panorama I pp. 27-38। Volumen 101 Número 18। Enero-junio I 2016 I La reconstrucción de las memorias de la UP se enmarca dentro de este escenario de empoderamiento de las víctimas con el que se busca saber la verdad sobre su genocidio y los mecanismos para obtener la justicia y la reparación que les corresponde. A través de la reconstrucción de sus memorias, este movimiento busca dar a conocer a la ciudadanía que sus sueños siguen vivos y que las lecciones del pasado, si bien nos deben servir para la construcción de nuestro presente y futuro, también nos enseñan que las luchas por la democracia y la paz continúan siendo el adalid para construir un país diferente.

Para un movimiento político que ha sido blanco de múltiples violaciones a los derechos humanos, la construcción de las memorias no es una tarea fácil. Sin embargo, la apuesta por la reconstrucción de la memoria histórica de la UP permitirá que su experiencia se visibilice, se conozca y se comprenda la importancia de la diferencia, la democracia y la construcción de la paz.

La memoria, para Calveiro (2006), plantea un doble movimiento: recuperar los sentidos que el pasado tuvo para sus protagonistas y descubrir los sentidos que esa memoria puede tener para el presente. Se trata, por tanto, de una conexión de sentidos que permita reconocer y vincular los procesos como tales, con sus continuidades y sus rupturas, antes que la rememoración de acontecimientos, entendidos como sucesos extraordinarios y aislados.

La reconstrucción de la memoria histórica de la UP busca justamente la vinculación de los procesos históricos con el presente y futuro del país y no su comprensión a partir del dolor que ha significado su genocidio. Las memorias de este movimiento político más que reivindicar a los muertos que han caído producto del irrespeto a los derechos humanos, reclaman la vida y los sueños que han representado a la UP. Los sueños de transformación y cambio para la construcción de una sociedad en paz y, por sobre todo, un país democrático que respete la diferencia.

\section{DIGNIFICACIÓN DE LAS VÍCTIMAS DE LA UP: PUEDEN MATAR UNA FLOR, PERO NO LA PRIMAVERA}

E1 ejercicio de recuperación de la memoria histórica contribuye a la dignificación de las víctimas y las comunidades afectadas dentro del conflicto armado. En el desarrollo de estos procesos de reconstrucción de memorias, se rescatan las voces para superar el silencio que impuso las situaciones de violación a los derechos humanos. Estas voces que fueron acalladas pero que quieren volver a hablar son el inicio de la reconstrucción del tejido social, que permite el desarrollo de sociedades democráticas, activas políticamente y que buscan continuamente el ejercicio de su ciudadanía. 
Para la Comisión Nacional de Reparación y Reconciliación, Área de Memoria Histórica (2009), la recuperación de la memoria histórica tiene un efecto muy importante entre las víctimas, ya sean consideradas individual, ya colectivamente: su dignificación y la de sus familiares. El trabajo de recuperación de la memoria debe rescatar, fundamentalmente, la dignidad de las víctimas, sus acciones, sus esfuerzos, su enorme capacidad de resistencia, creatividad y rehabilitación.

La recuperación de la memoria histórica para la UP ha generado importantes procesos de dignificación, los cuales se han manifestado en su capacidad de resistencia al mantener los sueños que un día tuvieron, en su capacidad de organización y en la búsqueda de la verdad, la justicia, la reparación y las garantías de no repetición. Para los sobrevivientes de la UP, el genocidio mató sus sueños, pero no su capacidad de soñar y, por esto, después de dos décadas del genocidio cometido contra esta organización política, no se piensan desde la memoria del sufrimiento y la guerra, sino desde los sueños y la esperanza.

La dignificación de las víctimas, como uno de los elementos consustanciales de los procesos de recuperación de la memoria histórica, permite mirar al futuro, reconstruir identidades, revalidar proyectos $y$, en esencia, construir memoria para el porvenir. Entender los procesos de memoria histórica desde la dignificación de las víctimas evita exaltar sentimientos de venganza, revictimizar a las personas y asumir a las víctimas en y desde el dolor.

Ahora bien, en función de comprender las dinámicas que generaron el genocidio de la UP y los procesos de recuperación de su memoria histórica y dignificación de las víctimas que actualmente se están llevando a cabo, se hace necesario hacer una reconstrucción histórica del movimiento político y de las circunstancias que generaron su victimización. Este documento busca entender en qué contexto surgió la UP, qué ideario alimentó su plataforma política, cuáles fueron los alcances electorales en el ámbito nacional y el genocidio del que fue objeto.

\section{LA UP: MEMORIAS PARA LA PAZ}

La UP surgió como una convergencia de fuerzas políticas dentro del proceso de negociación adelantado a mediados de la década de 1980 entre el Gobierno del presidente Belisario Betancur y las Fuerzas Armadas Revolucionarias de Colombia (FARC).

En 1984, se firmaron en La Uribe, municipio de Mesetas, departamento del Meta, los Acuerdos de la Uribe. Con estos acuerdos, se pactó un conjunto de compromisos entre las partes, en los que se destacó el surgimiento de un movimiento de oposición como mecanismo que permitiría que la guerrilla se incorporara paulatinamente a la vida legal del país. Las condiciones que lograrían ese tránsito a la legalidad consistían en un compromiso oficial para garantizar plenamente los derechos políticos a los integrantes de la nueva formación, y la realización de una serie de reformas democráticas para el pleno ejercicio de las libertades civiles. A partir de este momento, las FARC comenzarían su trabajo político agenciando el fortalecimiento de un nuevo movimiento político (Cepeda, 2006).

Según los acuerdos pactados, en una primera fase, se planteó un cese al fuego y de hostilidades declarados por las partes. En un segundo momento, el Gobierno se comprometió a promover reformas de ampliación de la democracia, como la elección de alcaldes y gobernadores y el estatuto para la oposición. Además, declaró su determinación de impulsar una reforma agraria y desmontar cualquier grupo paramilitar. Con la consolidación de estas medidas, la guerrilla en tregua iría transformándose a movimiento político legal en el marco democrático.

Ahora bien, la proyección del movimiento desde sus inicios fue la convocatoria de diversos sectores de la población para que lo nutrieran de manera amplia y pluralista. De esta forma, la UP se constituyó en un movimiento amplio de convergencia democrática alimentado de las más variadas fuerzas nacionales y regionales de izquierda, liberales, conservadores y sectores cívicos, que buscaban un cambio en las prácticas políticas del país. Aun cuando no se pretendía cambiar el régimen estatal, se buscaba reformarlo en materia social, política y económica planteando la redistribución de la riqueza, el desmonte del paramilitarismo y la modernización del Estado. De igual forma, se denominó un movimiento político, contrario a toda concepción sectaria, excluyente o hegemónica (Ortiz, 2008).

En síntesis, la UP surgió como un desarrollo lógico de los acuerdos de La Uribe, en los cuales se estipuló que
I Panorama

I pp. 27-38

I Volumen 10

I Número 18

I Enero-junio

| 2016

| 29 
Yaneth Mora Hernández I

dic

los integrantes de las FARC tendrían derecho a organizarse, política, económica y socialmente según su libre decisión, para lo cual el Gobierno le otorgaría, de acuerdo con la Constitución y las leyes, las garantías y los estímulos pertinentes. Las FARC se comprometieron a hacer la plataforma del lanzamiento de la UP, la dotaron de una plataforma de lucha inicial y destacaron líderes suyos al trabajo político. Posteriormente, la UP fue adquiriendo su propia dinámica política, cuando se nutrió de sectores regionales del Partido Liberal, sectores independientes y de izquierda. Un año después, en 1985, la UP hizo su primer congreso constitutivo donde se definió su programa político con una Dirección Nacional y se constituyó como una organización civil, política, legal y legítima.

\section{LA GRAN ACOGIDA DE LA UP Y SU ÉXITO EN LAS ELECCIO- NES LOCALES, MUNICIPALES Y NACIONALES}

Al participar por primera vez en contiendas electorales, después de un año de haberse constituido como partido político, la UP obtuvo la mayor votación lograda hasta ese momento por cualquier otro partido de izquierda. Sin tener una estructura de tanta trayectoria como la de otros partidos, consiguió unos resultados políticos organizacionales traducidos en juntas patrióticas, en las cuales hacían presencia sectores barriales, locales, veredales y gremiales, que votaron tanto para presidente como para cuerpos colegiados. La UP obtuvo en las elecciones de 1986329000 votos, correspondientes a $4.5 \%$ del censo electoral, eligió 5 senadores, 9 representantes, 14 diputados, 23 alcaldes y 351 concejales. En menos de 6 meses, la UP ya registraba 2229 juntas patrióticas y en 572 actos políticos habían reunido a más de un millón de personas.

Con estos resultados electorales, la UP subvertía el orden que el establecimiento había impuesto durante tantos años y hacía prever que prontamente iba a ostentar el poder político en todo el territorio nacional. El éxito en las elecciones de 1986 generó un gran optimismo, pues nunca antes un partido diferente de los tradicionales había logrado estos resultados (Romero, 2011).

Número 18। Enero-junio I

2016 I

En algunas zonas del país, la UP se constituyó como una fuerza política sin precedentes. La región de Urabá, zona de masiva producción de banano para la exportación, fue una de las regiones donde la UP tuvo mayor solidez. La UP logró en Urabá su mejor éxito al colocarse como segunda fuerza política en los municipios de Chigorodó, Turbo y Murindó, y aportar una importante votación en los municipios de Apartadó y Mutatá. La posterior conquista de las alcaldías populares de Apartadó y Turbo, esta última en coalición con los sectores del Partido Liberal, conformó en 1988 la solidez y la amplitud del trabajo político de masas desplegado por el Partido Comunista, la UP y los frentes guerrilleros regionales (Ortiz, 2008).

En el departamento del Meta, la UP también tuvo una importante participación. En 1988, con la primera elección popular de alcaldes, la UP logró las alcaldías de Vistahermosa, Mesetas, Lejanías y El Castillo. Por otra parte, en la mayoría de los municipios logró representación en los consejos y accedió de manera significativa a la Asamblea Departamental.

En este orden de ideas, ya hacia finales de la década de 1980, la UP se convirtió en una fuerza con opción de poder nacional, y su candidato a la presidencia, Bernardo Jaramillo Ossa, figuraba en las encuestas como uno de los favoritos, con una intención de voto que superaba el millón de sufragios.

\section{LA PAZ Y LA DEMOCRACIA EN EL IDEARIO POLITICO DE LA UP}

La UP planteó una plataforma política pensada y estructurada para la construcción de un país democrático y en paz. La democracia real fue uno de los ejes centrales de su propuesta política, y esta se entendía a partir de un conjunto de acciones que pretendían romper con el orden tradicional, tales como el levantamiento del estado de sitio, el respeto a los derechos humanos, el desmonte del monopolio de los partidos tradicionales y la apertura de escenarios de participación popular a las mayorías. Este conjunto de acciones entendían la democracia desde una mirada amplia, en la que la participación política abarcaba nuevas instancias más profundas y activas.

Durante la década de 1980, el contexto antidemocrático en el país se caracterizaba por la continuidad bipartidista que había dejado el Frente Nacional. Este modelo tradicional no había podido apartarse de sus actuaciones de exclusión y represión política a terceros partidos, movimientos, protestas sociales, organizaciones y agremiaciones de base. Asimismo, la extralimitación de 
las facultades de las fuerzas militares dejaba en entredicho el carácter de Estado social de derecho. Este fue el contexto antidemocrático en el que la UP planteó la necesidad de cambios y transformaciones estructurales.

Además de la democratización de las diferentes instancias del Estado, la UP planteó una política económica volcada hacia el bienestar social donde el desarrollo económico estuviera en función de las mayorías. Esta política económica implicaba mejores condiciones de vida a partir del alza de sueldos, planes de empleo digno, reducción de gastos militares e incremento en presupuesto para la salud, la educación, la ciencia, la cultura, la agricultura y las obras públicas. Las disposiciones en educación y salud marcaron un punto de quiebre, pues por primera vez a estos dos sectores se les daba la importancia necesaria que le correspondía para el bienestar social de la nación.

El concepto de soberanía nacional también tenía una importante participación en la plataforma política de este movimiento. La nacionalización de los recursos minerales, de la banca y los monopolios, la negativa a pagar la deuda externa y seguir las imposiciones de los organismos multilaterales, se constituyeron en los ejes centrales de una política que retomaba la necesidad de girar su vista ya no hacia los intereses extranjeros, sino a las necesidades nacionales y el bienestar de las y los colombianos.

El carácter progresista del programa político de la UP se vio reflejado en un conjunto de apuestas y proyectos que no habían sido tan siquiera contemplados por los ya conocidos partidos Liberal y Conservador. Su plataforma contemplaba a los diferentes sectores de la sociedad en sus necesidades sociales y en la reivindicación de sus derechos. Campesinos, indígenas y mujeres por primera vez eran contemplados como sujetos que merecían un trato especial. Los campesinos fueron contemplados a partir de la necesidad de una real y democrática reforma agraria, las comunidades indígenas a partir de su dignificación y el respeto a sus derechos y las mujeres a partir de políticas de igualdad y reivindicación de derechos.

En síntesis, esta plataforma se enmarcó en un proyecto de paz entendido desde la justicia social y el respeto a los derechos humanos. La paz fue concebida como el vehículo que permitiría una sociedad democrática, incluyente y con unas condiciones de vida digna. Su proyecto alrededor de la paz tendría que ser la columna vertebral para avanzar y dejar atrás los largos periodos de violencia política que habían desangrado al país y habían generado tanta intolerancia y exclusión.

\section{FIN DE LOS DIÁLOGOS DE PAZ ENTRE EL GOBIERNO Y LAS FARC}

El sueño de la UP pronto se vio trastocado a causa del fin de los diálogos de paz. Este proceso entre el Gobierno de Belisario Betancur y las FARC estuvo mediado por un sinnúmero de obstáculos que pronto darían fin a los Acuerdos de Cese al Fuego, Tregua y Paz inicialmente pactados. Esta situación fue determinante no solo para los anhelos de paz que se vieron frustrados, sino en el desarrollo de lo que posteriormente fue el genocidio contra la UP.

En el desarrollo de los diálogos de paz, las fuerzas militares se constituyeron en una de las mayores limitantes para materializar el ideal de paz. Este estamento se opuso de manera radical a las disposiciones del presidente de la república, y se afianzó en las atribuciones dadas por los Gobiernos anteriores, sobre todo en los alcances otorgados durante el Frente Nacional y el Estatuto de Seguridad.

Para Ortiz (2008), el fracaso en el proceso de paz tuvo que ver con varios factores que siempre han caracterizado a Colombia: gran debilidad gubernamental, incapacidad para manejar a la institución militar, el orden público y el accionar radical del movimiento guerrillero. Durante el desarrollo de los diálogos de paz, se generaron varios obstáculos que sepultaron los acuerdos: el presidente no contó con un verdadero partido de Gobierno, el distanciamiento entre el poder civil y el poder militar en torno a la paz, el cual no permitió la construcción de un proyecto de reconciliación nacional, y por último la fragmentación de los grupos guerrilleros, lo cual no permitió que se presentaran en unidad.

En síntesis, los Acuerdos de Paz de 1984 fracasaron producto de la incapacidad del presidente Belisario Betancur de aislar a quienes desde el interior de su Gobierno entorpecían la vigencia de los acuerdos y por sobre todo la radicalidad de unas fuerzas militares que no estaban dispuestas a verse desplazadas en su accionar militar. Asimismo, la impotencia del presidente para acabar con

\section{democracia}

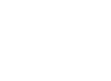

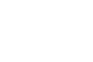

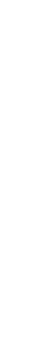


el paramilitarismo hizo que este se propagara por todo el territorio nacional y fuera posteriormente uno de los protagonistas del acrecentamiento del conflicto.

Yaneth Mora Hernández I

A finales de 1986, las FARC dieron por terminada la tregua y ordenaron que los líderes que habían dispuesto para el trabajo político dentro de la UP regresaran a los frentes de la lucha armada. Con esto, se dio por terminado los acuerdos y se desvaneció así cualquier continuidad de diálogo con esta agrupación.

\section{INICIA EL GENOCIDIO DE LA UP}

Para las víctimas de la UP, el genocidio político cometido contra este movimiento se ha inscrito en un proceso de exterminio de fuerzas políticas de oposición, y se ha convertido en un caso paradigmático de aniquilación de los miembros y líderes de un grupo a causa de sus convicciones ideológicas, así como de la persecución de sus simpatizantes y la destrucción de su entorno social. El conjunto de acciones criminales contra esta organización no se trata de una eliminación aleatoria, sino de un genocidio en su acepción más clara.

La Asamblea General de las Naciones Unidas define el genocidio como una negación del derecho de existencia a grupos humanos enteros, entre ellos los raciales, religiosos o políticos. Esta definición de genocidio posteriormente fue acogida en el artículo 4 del estatuto del Tribunal Penal Internacional para la Antigua Yugoslavia, el estatuto del Tribunal Penal Internacional para Ruanda y el Estatuto de Roma, por el que se creó la Corte Penal Internacional.

El carácter de la palabra genocidio comprende un conjunto de implicaciones que se enmarcan en lo acontecido con la UP. Un genocidio se diferencia del asesinato en serie en cuanto este último consiste en el asesinato sucesivo y periódico de personas aisladas, mientras que el genocidio es una negación del derecho de existencia a grupos humanos en su conjunto. Este tiene un carácter masivo, por lo que necesita de la colaboración efectiva de una estructura social.

El genocidio de la UP respondió a un conjunto de planes de exterminio diseñados por una estructura organizada de militares, paramilitares y fuerzas oscuras del Estado, que, desconociendo el carácter democrático del país, quebrantaron la institucionalidad y cometieron los peores crímenes y violaciones a los derechos humanos.

Ahora bien, el genocidio de la UP inició a partir del rompimiento de los acuerdos de paz entre el Estado y las FARC. A partir de este momento, no solo se suprimió cualquier posibilidad de una salida negociada al conflicto, sino que también se dio vía libre a un proceso de eliminación sistemática contra los militantes de la UP. Si bien el inicio de los hostigamientos y atentados entra los militantes de la UP había iniciado desde 1984, fue a partir del fin de los diálogos de paz que fue más abierto y frontal el exterminio de este movimiento.

Para Cepeda (2006), los miembros de la UP, una vez concluidos los diálogos, quedaron en una situación de alto riesgo, pues, al ser acusados abiertamente de ser portavoces de la insurgencia armada, no se les brindó ninguna protección efectiva. El genocidio a que se vio sometida la UP a partir de este momento se ha configurado como uno de los momentos más luctuosos en la historia contemporánea de Colombia, pues, al querer impedir a toda costa que este movimiento tuviera representación en las instituciones del Estado o en los cuerpos colegiados, se inició la más fuerte política de eliminación.

Lo que se había convertido en una victoria histórica de la UP por su éxito en las elecciones significó paradójicamente su desgracia. Por una parte, con la disculpa de combatir a la guerrilla, los escuadrones de la muerte iniciaron la tarea de exterminio con una ola de crímenes selectivos contra senadores, representantes, concejales y diputados de la UP. En una década, la UP perdió 145 concejales, todos asesinados en la campaña de exterminio, lo cual significa 14 por año y más de un líder cada mes. Además de esto, 15 alcaldes en ejercicio, 9 candidatos a alcaldías, 11 diputados, 12 candidatos a asambleas, 3 representantes a la Cámara, 3 senadores de la república y 2 candidatos presidenciales cobraron la racha de homicidios (Romero, 2011).

Además de los crímenes contra sus líderes políticos, el movimiento popular también se vio profundamente afectado. Miles de simpatizantes de la UP debieron abandonar sus tierras en un desplazamiento enorme para salvar sus vidas. En las zonas donde este movimiento era la primera fuerza política, el terror daba sus 
frutos a partir de múltiples masacres contra el movimiento en menos de diez años.

Frente a esta catástrofe humana, la institucionalidad política no solo guardó silencio, sino que de una manera implícita justificó esta situación al relacionar el movimiento como brazo político de la subversión. Para la nueva administración liberal de Virgilio Barco, la supuesta ambigüedad del nuevo movimiento explicaba la acción paramilitar. Con esto, se desconocía que los muertos no eran combatientes, sino civiles desarmados, con una larga tradición de acción política legítima.

\section{EL PARAMILITARISMO Y SU PAPEL PROTAGÓNICO EN EL GENOCIDIO}

La arremetida del paramilitarismo desde la década de 1980 y su accionar delictivo contra el movimiento popular y en este caso contra la UP configuró el genocidio al que estaba siendo sometido. En las zonas del país donde la UP había tenido un fuerte respaldo electoral, el paramilitarismo llegó y estableció sus más horrendos mecanismos de terror. La relación era directamente proporcional: a mayor respaldo electoral mayor número de asesinatos selectivos. Entre 1986 y 1988, años electorales, se registraron hechos de criminalidad generalizada en las zonas de influencia de la UP. Esa violencia se hizo sentir en especial en aquellos municipios y ciudades donde el grupo político obtuvo poder local y comenzó a desarrollar programas de Gobierno, que incluían la construcción de obras públicas, hospitales y escuelas.

Uno de los fortines electorales de la UP fue el departamento del Meta, y fue allí también donde el número de militantes y líderes políticos de este movimiento fueron significativamente eliminados, desplazados y desaparecidos. Hacia 1988 la UP logró alzarse con 16 alcaldías y 256 concejales. E1 Meta se volvió el reducto electoral del movimiento, pues en esta región fueron elegidos 4 alcaldes y 47 concejales. Los paramilitares vieron este triunfo como una evidencia de la influencia de las FARC por ser su santuario natural, lo cual generó que este departamento fuera uno de los primeros objetivos de los grupos de autodefensas, entre estos los comandados por El Mexicano y Víctor Carranza.

Entre 1986 y 1988 unos 300 militantes de la UP fueron asesinados en el Meta. En El Castillo, uno tras otro, fueron destituidos o asesinados cuatro alcaldes de la UP junto con otros funcionarios de la Administración local de la misma filiación. En este mismo municipio, en el corregimiento de Vista Hermosa, los paramilitares que ya contaban con 5000 unidades realizaron una de sus primeras masacres, donde asesinaron a 17 militantes de la UP.

En el Urabá antioqueño, la situación no fue diferente. En 1986, el nombre de Fidel Castaño Gil ya era asociado en Segovia con la fundación del grupo paramilitar Muerte a los Revolucionarios del Nordeste (MRN), que recién había iniciado una campaña de amenazas y muerte contra líderes regionales de la UP y que meses después reivindicarían los asesinatos de varios líderes políticos de este movimiento y sindicalistas, ya no en el nordeste antioqueño, sino en Urabá.

La emergencia del MRN en 1986 coincide con la primera participación electoral de la UP, considerada, como ya se ha señalado, un fenómeno electoral, al obtener la más alta votación de izquierda hasta el momento. Jaime Pardo Leal, máximo dirigente de la UP y candidato presidencial de esa agrupación política, quien posteriormente sería asesinado, acusó públicamente a miembros de las Fuerzas Armadas acantonados en Segovia y Remedios de estar implicados con el MRN en la muerte y desaparición selectiva de los líderes de la UP. A finales de 1987, las amenazas del MRN se concentran en los municipios de Remedios, Segovia, Zaragoza y el Bagre, donde el año anterior la UP había obtenido una alta votación.

El caso de la masacre de Segovia es bastante diciente y evidencia no solo el accionar paramilitar, sino su connivencia con sectores de las Fuerzas Militares en la eliminación sistemática de la UP. En las elecciones de 1988, este movimiento ganó las alcaldías de Remedios y Segovia y conquistó un gran número de concejales en el conjunto de los municipios del nordeste antioqueño. La conquista de la alcaldía de Segovia por Rita Ivonne Tobón implicó que el Partido Liberal fuera desbancado.

Desde entonces los atentados contra la vida de importantes dirigentes regionales de la UP preludiaron el anunciado gran golpe mortal que llegó el 11 de noviembre de 1988 y que se ha constituido en una de las peores masacres de la historia reciente del país. Ese día, tres camperos con hombres armados recorrieron las principales calles del pueblo y dejaron 43 personas muertas y
La Unión

Patriótica:

memorias para

la paz y la democracia

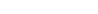

.

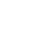


50 heridas. En su retirada, los asesinos utilizaron la vía sobre la cual está el cuartel Bomboná sin que los militares se dieran por enterados (Ramírez, 1997).

Yaneth Mora Hernández I

Los grupos paramilitares se especializaron en el empleo de métodos de tortura y de tratamientos crueles practicados públicamente como forma de aterrorizar a la población, y prevenirla acerca de las implicaciones que tenía su simpatía hacia los militantes de izquierda. E1 conjunto de masacres realizadas tuvieron como resultado el aislamiento social de los sobrevivientes o el desplazamiento de quienes se negaban a abandonar las regiones. En Segovia, los paramilitares antes de marcharse del pueblo dejaron la consigna: "No vuelvan a votar por la Unión Patriótica, pues eso les causa la muerte”.

\section{PLANES DE EXTERMINIO ENMARCADOS EN EL GENOCIDIO}

El genocidio de la UP se realizó a partir de un conjunto de planes de exterminio diseñados y ejecutados para establecer estrategias y métodos de eliminación en diversas modalidades: masacres, desplazamientos, desaparición forzada, amenazas, hostigamientos, exilios, asesinatos, encarcelamientos, destrucción de sedes, despojo de personería jurídica, invisibilización, negación del crimen e impunidad. Estos planes que fueron conocidos como la Operación Cóndor (1985), el Plan Baile Rojo (1986), el Plan Esmeralda (1988) y el Plan Golpe de Gracia, cobraron la vida de miles de militantes, líderes políticos y simpatizantes de la UP. Su puesta en operación buscó acabar con las bases de la organización política en varias regiones del país y con sus líderes más destacados.

Cada uno de estos planes buscó la eliminación de este movimiento a partir de múltiples estrategias y diferentes escenarios municipales, locales o nacionales. Adicionalmente, la colaboración de algunos sectores de las Fuerzas Militares y de los paramilitares se convirtió en la mejor alianza para el desarrollo de estos planes de manera exitosa.

Número 18।

El Plan Esmeralda (1988), por ejemplo, tuvo por objeto barrer con la influencia de la UP y el Partido Comunista en los departamentos del Meta y Caquetá; dos de las regiones en las que se obtuvieron los mejores resultados en los comicios, que superó incluso a los partidos 34 Liberal y Conservador. Adicionalmente, los dirigentes de izquierda denunciaron que la Operación Cóndor y el Plan Baile Rojo fueron concebidos para socavar las estructuras de dirección nacional del movimiento y asesinar o secuestrar a sus dirigentes elegidos a las corporaciones públicas (Cepeda, 2006).

La magnitud del genocidio es incalculable. Según la Corporación Reiniciar, el número de víctimas entre 1984 y 2006 es de 6528 personas, de las cuales cerca de la mitad fueron asesinadas y desaparecidas forzadamente. Tal como lo señala Iván Cepeda, de ese mismo cuadro hacen parte detenciones masivas y arbitrarias contra los miembros sobrevivientes del movimiento, poblaciones desplazadas de sus zonas de influencia, decenas de atentados dinamiteros contra sus oficinas y familias enteras exiliadas.

Durante este periodo, se incrementaron considerablemente las cifras de las poblaciones desplazadas en zonas de influencia de la UP. Adicionalmente, aumentó el número de personas y familias exiliadas. En 1996, luego de un atentado del que salió ilesa la presidenta de la UP, Aída Abella Esquivel, tuvo que exiliarse. Según las cifras del movimiento, en esta etapa se refugiaron cerca de 200 familias perseguidas, por el hecho de contar con uno o varios miembros de la organización.

En síntesis, la acción criminal contra la UP se extendió por todo el territorio nacional. Reiteradamente los líderes del movimiento político denunciaron de manera pública y ante organismos del Estado el crimen sistemático de que eran víctimas sus miembros y simpatizantes, pero el silencio y la falta de garantías para su actividad política fue total (Campos, 2003).

Como una forma simbólica, pero también certera de acabar con la UP como partido político, el 30 de septiembre de 2002 el Consejo Nacional Electoral expidió la Resolución 5659 en la que le retiró el estatuto legal para el funcionamiento del partido político Unión Patriótica. La justificación de esta medida consistió en que el grupo no reunía el número de sufragios electorales necesarios (50 000 votos) para mantener su personería jurídica.

Ese año, la UP obtuvo 1185 votos para Cámara, y ninguno para Senado ni para las elecciones presidenciales, porque el partido no tenía candidatos. Como nadie salió 
elegido y tampoco consiguió los votos necesarios para existir, el partido perdió la personería jurídica.

La ley electoral determina que un partido político pierde sus derechos si no alcanza un determinado número de votos o no se presenta a elecciones. Esta medida fue tomada de manera ortodoxa, desconociéndose que la UP fue objeto de una política de exterminio que no sufrieron otros partidos.

\section{EL SILENCIO Y LA IMPUNIDAD}

El genocidio cometido contra la UP evidenció los niveles de intolerancia política existentes en el país. Durante todo el proceso de exterminio no hubo pronunciamientos de ningún sector social o institucional. Las alrededor de 6500 víctimas no tuvieron más que el consuelo de sus familiares y compañeros, pues ni la Iglesia, ni la institucionalidad del Estado, ni los partidos políticos, ni los medios de comunicación se pronunciaron por el genocidio que se estaba cometiendo contra todo un movimiento político.

Pero sin duda, y tal como lo señala Romero (2011), al horror del genocidio habrá que sumarle el horror a la impunidad. Hasta la fecha, y según el coordinador de la Unidad de Derechos Humanos de la Fiscalía, se han contabilizado 1316 víctimas y 136 sentencias condenatorias, que involucran a 191 personas, 90 sentencias con aceptación de cargos, para 106 personas y 11 absolutorias para un total de 238 fallos y 297 personas comprometidas. Estas cifras evidencian la limitación de la administración de justicia en el país y por sobre todo los altos niveles de impunidad para un caso de las magnitudes del de la UP.

El genocidio político del que fue objeto la UP no corresponde a un conjunto de crímenes individuales sin interconexión alguna, sino a la eliminación de todo un colectivo humano, para el cual fue necesario la colaboración efectiva de una estructura social. Lo anterior tiene unas connotaciones respecto de la administración de justicia. El hecho de que el crimen de la UP se configure como un genocidio implica, tal como lo señala el representante a la cámara Iván Cepeda, la necesidad de una investigación que metodológicamente pudiera aclarar no solo hechos particulares, sino el contexto, la responsabilidad, el modus operandi, la intencionalidad y los patrones que se han utilizado para cometer el genocidio.
Las acciones de la Fiscalía para llevar a cabo una investigación conjunta que permita desentrañar la estructura organizada que posibilitó las violaciones, sus causas, sus beneficiarios y sus consecuencias no ha sido posible. La falta de unidad procesal en lo que corresponde a la investigación de manera conjunta de los crímenes y magnicidios de la UP no ha permitido resolver la grave situación de impunidad.

Por lo anterior, la Dirección Nacional de la UP, la Corporación Reiniciar y la Comisión Colombiana de Juristas presentaron el caso del genocidio de la UP ante la Comisión Interamericana de Derechos Humanos $(\mathrm{CIDH})$ en 1993. Casos como el magnicidio del senador Manuel Cepeda Vargas también fue llevado ante la $\mathrm{CIDH}$ de forma individual por sus circunstancias particulares en las que participaron conjuntamente miembros del Ejército nacional de diverso rango y miembros de grupos paramilitares.

La CIDH admitió el caso colectivo del genocidio de la UP y en su informe de admisión señaló: "Los hechos alegados por los peticionarios exponen una situación que comparte muchas características con el fenómeno de genocidio y se podría entender que sí lo constituyen, interpretando este término de conformidad con su uso corriente". Este es un paso que busca por medios supranacionales acceder al derecho a la verdad y a la justicia en cuanto la justicia nacional ha sido muy limitada.

En desarrollo del procedimiento ante la CIDH, el Estado y los peticionarios comenzaron a explorar los pasos preliminares conducentes a una eventual solución amistosa. En marzo de 2000, suscribieron un acuerdo para propender al esclarecimiento de los hechos y a la realización de los derechos a la verdad, la justicia y la reparación integral. Sin embargo, en 2006, se dio una ruptura a este proceso, luego de que el Gobierno de Uribe Vélez diera un tratamiento poco respetuoso y estigmatizara a las víctimas y familiares de la UP.

A partir de esa situación, se solicitó a la CIDH que se diera por concluida esta etapa "amistosa" y se pasara a la etapa de fondo, en la que se debe tomar una decisión sobre la responsabilidad del Estado colombiano en el exterminio de la UP.
La Unión

Patriótica:

memorias para

la paz y la

democracia 


\section{PASOS HACIA LA VERDAD, LA JUSTICIA Y LA REPARACIÓN COLECTIVA EN EL CONTEXTO ACTUAL DE LOS DIÁLOGOS $D E P A Z$}

Yaneth Mora Hernández I

Tras dos décadas del inicio del genocidio contra la UP, los pasos hacia la verdad, la justicia y la reparación han sido tímidos. Los procesos de reconstrucción de la memoria histórica de la UP, si bien están permitiendo unos niveles de comprensión de lo que pasó, generando procesos paulatinos de dignificación a las víctimas, todavía merecen mayor visibilidad y atención.

En el proceso de construcción de la verdad histórica, todavía hay mucho camino por recorrer. En este proceso, se tiene que llegar a saber las verdades que rodearon el genocidio, sus auténticos autores, sus estructuras, las instituciones y los aparatos que lo provocaron y financiaron. Se tiene que saber qué pasó y quiénes son sus responsables, pues solo así se podrá trascender en los procesos de verdad, justicia, reparación y garantías de no repetición.

Con respecto a la justicia para el caso del genocidio de la UP, esta ha sido en extremo limitada. La búsqueda de justicia sigue siendo un elemento fundamental para que este proceso tan doloroso no se quede en el olvido y las víctimas y el conjunto de la sociedad colombiana comprenda que lo que pasó no puede volver a ocurrir. Sin embargo, las acciones de la justicia nacional para llevar a cabo una investigación conjunta que permita desentrañar el entramado de relaciones y alianzas que determinaron el genocidio de este movimiento político no se han dado. La impunidad absoluta ha sido constante para el caso de la UP en el curso de las últimas décadas, hasta el punto de que las víctimas confían más en los mecanismos de justicia supranacional.

Justamente, un hecho paradigmático en los procesos de verdad, justicia y reparación para las víctimas de la UP ha sido la condena de la Corte Interamericana de Derechos Humanos al Estado colombiano por el crimen de Manuel Cepeda en junio de 2010.

Número 18।

La Corte Interamericana estableció que el Estado colombiano, además de ser responsable por acción y omisión del homicidio político contra el senador Cepeda, fue responsable de haber violado un conjunto de derechos fundamentales, haber negado la justicia y que ordenaron y planificaron el asesinato, haber negado la alianza criminal entre los sectores de las Fuerzas Militares y los grupos paramilitares y haber atentado contra la libertad de expresión de este líder de la UP.

Esta condena representó un importante avance en la búsqueda de la verdad y la reparación en un caso que, si bien fue analizado de manera individual, evidencia el entramado de relaciones criminales que rondaron el genocidio contra la UP.

Otra sentencia de gran importancia en lo que corresponde al caso de la UP es la relacionada con la masacre de Segovia. El 14 de marzo de 2011, la Corte Suprema de Justicia resolvió por unanimidad acusar a César Pérez García como presunto determinador de la masacre de Segovia ocurrida el 11 de noviembre de 1988 y en la que perdieron la vida 43 personas y quedaron decenas de heridos. Pérez García, conocido político liberal de Antioquia, expresidente de la Cámara de Representantes de 1986, fue llevado a prisión acusado por varios exjefes paramilitares de ser el autor intelectual de la masacre de Segovia, tras haber perdido en 1988 las elecciones en dicho municipio a manos de la UP cuando tuvo lugar la primera elección popular de alcaldes.

Este es un caso emblemático en que la justicia colombiana ha fallado y que aporta luces de los móviles y las circunstancias que generaron esta masacre, pero por sobre todo llegando a los actores intelectuales que orquestaron y maquinaron este delito. Aun cuando esta fue una sentencia de carácter individual, es un paso que se da en el largo camino hacia la justicia.

Por último, la reparación en el caso de la UP es un factor decisivo en cuanto debe determinar no solo las responsabilidades del genocidio, sino el papel de las víctimas y sus derechos. La Ley de Víctimas 1441, sancionada por el Gobierno en 2011, es un paso adelante en este proceso de reparación, en cuanto ha sido la primera iniciativa que plantea la necesidad de reparación integral a las víctimas del conflicto. Esta ley se enmarca en un proceso que ya han iniciado las víctimas de la UP, en el que se busca la verdad de lo que pasó, la justicia para quienes son culpables y la reparación colectiva para las víctimas.

La restitución de la personería jurídica de la UP en julio de 2013, luego de una década de batallas jurídicas, se 
ha convertido en un acto importante en los procesos de reparación. Este movimiento político logró que el Consejo de Estado acogiera sus argumentos y le devolviera la vida en el escenario político electoral. Sin embargo, hay mucho camino por recorrer y la personería jurídica después de años de exterminio implica un gran desafío.

Ahora bien, en el actual proceso de paz que se lleva a cabo en La Habana (Cuba) entre el Gobierno nacional y las FARC, el caso de la UP vuelve a tener protagonismo. En miras a lograr un proceso de paz ante la reconciliación, el genocidio de la UP debe ser conocido y la verdad sobre este debe saberse; solo así podremos avanzar en un proceso real de paz, en el que las víctimas sean resarcidas respecto de su derecho a la verdad, la justicia y la reparación. Tal como lo señala Iván Cepeda, "la UP es imprescindible en cualquier proceso político de cara a la reconciliación. Lo sucedido con la UP corresponde a ese tipo de crímenes con los cuales no puede la sociedad colombiana encontrar la paz hasta su esclarecimiento". Solo la verdad y la justicia sobre el crimen contra la UP pueden generar pasos reales hacia la construcción de la paz.

\section{CONCLUSIÓN}

Para los y las colombianas, lo acontecido con la UP debe conocerse, entenderse y buscar los mecanismos pedagógicos para divulgarse. Los niños y jóvenes de esta generación deben conocer lo que ha sido la UP, los sueños y las esperanzas que articularon sus propuestas, pero también el escenario antidemocrático que generó su genocidio. El conocimiento de nuestra historia nos debe servir para comprender que un genocidio como el cometido contra la UP no puede volver a ocurrir y que esta dura lección nos debe servir para mirar hacia el futuro.

Un elemento central en la construcción de memoria y verdad histórica es su visibilización. Quienes no son víctimas directas del genocidio de la UP desconocen por completo lo que ha pasado con este movimiento político e ignoran la relevancia de su propuesta y la riqueza de sus ideas para la construcción de una democracia real. Niños, jóvenes e incluso adultos desconocen qué es la UP, en qué contexto surgió, las ideas políticas que estructuraron su plataforma y, por supuesto, el genocidio del que ha sido objeto.
Este desconocimiento de lo que ha sido la UP es lesivo en el momento de comprender nuestro pasado reciente y las lecciones que sobre este debemos aprender. De ahí la importancia de generar espacios de visibilización y reflexión que permitan sensibilizar a quienes no han sido víctimas directas sobre este proceso de tal forma que se comprenda la importancia de la democracia y la defensa de los derechos humanos.

Para la población víctima, estos procesos de visibilización y sensibilización también son importantes, en cuanto permiten que las víctimas puedan afirmarse desde la dignidad al verse y entenderse como actores políticos que siguen reivindicando su derecho a la diferencia y a la tolerancia política.

\section{REFERENCIAS}

1. Calveiro, P. (2006). Los usos políticos de la memoria. En G. Caetano (comp.), Sujetos sociales y nuevas formas de protesta (pp. 359-382). Buenos Aires: Consejo Latinoamericano de Ciencias Sociales.

2. Campos, Y.(2003). Memoria de los silenciados: el baile rojo: relatos. Bogotá: Ceicos.

3. Castoriadis, C. (1989). La institución imaginaria de la sociedad. Barcelona: Tusquets.

4. Centro de Memoria, Paz y Reconciliación (2012). Bogotá, Ciudad Memoria. Bogotá.

5. Centro Nacional de Memoria Histórica (2013). ¿Basta ya! Colombia: memorias de guerra y dignidad. Bogotá: Centro Nacional de Memoria Histórica.

6. Cepeda, I. (2006). Genocidio político: el caso de la Unión Patriótica en Colombia. Revista Cetil, 1(2), 101-112.

7. Comisión Nacional de Reparación y Reconciliación, Área de Memoria Histórica (2009). Recordar y narrar el conflicto: herramientas para reconstruir memoria histórica. Bogotá: Fotoletras.

8. Halbwachs, M. (1990). Espacio y memoria colectiva. Estudios sobre las Culturas Contemporáneas, 3(8), 11-40.

I Panorama

I pp. 27-38

I Volumen 10

9. Jelin, E. (2002). Los trabajos de la memoria. Madrid: Siglo XXI.

I Número 18

I Enero-junio

10. Leal, F. (2002). La seguridad nacional a la deriva: del Frente Nacional a la posguerra fría. Bogotá: Alfaomega.
Patriótica:

memorias para

la paz y la 
11. Martín-Barbero, J. (1991). De los medios a las mediaciones. México: Gustavo Gili.

12. Ortiz Palacios, I. (2007). El genocidio politico contra la Unión Patriótica: visto por la prensa escrita 1984-2004. Bogotá: Universidad Nacional de Colombia.

Hernández |

13. Ortiz Palacios, I. (2008). Memoria narrada, narración de una historia: el genocidio político contra la Unión Patriótica. Bogotá: Universidad Nacional de Colombia.

14. Ramírez Tobón, W. (1997). Urabá, los inciertos confines de una crisis. Bogotá: Planeta.

15. Romero, R. (2011). Unión Patriótica: expedientes contra el olvido. Bogotá: Centro de Memoria, Paz y Reconciliación.

16. Serna, A. y Gómez, D. (2010). Cuando la historia es recuerdo y olvido: un estudio sobre la memoria, el conflicto y la vida urbana en Bogotá. Bogotá: Universidad Distrital Francisco José de Caldas.

17. Schindel, E. (2009). Inscribir el pasado en el presente: memoria y espacio urbano. Política y Cultura, 31, 65-87. 